\title{
COVID-19 and the dental damage stage: a comment
}

\author{
Rujitika Mungmunpuntipantip $^{1}\left[\right.$ [ $\cdot$ Viroj Wiwanitkit $^{2}$ (1)
}

Received: 22 February 2021 / Accepted: 23 March 2021 / Published online: 29 March 2021

(c) The Author(s), under exclusive licence to Japanese Society for Oral and Maxillofacial Radiology and Springer Nature Singapore Pte Ltd. 2021

\section{Dear Editor,}

We would like to share ideas on the publication "The relationship betweenCOVID-19 and the dental damage stage determined by radiological examination [1]." Sirin and Ozcelik noted that "The relationship detected between dental damage (DD) stage and the severity and prognosis of viral disease such as COVID-19 was found to be remarkable for extensive studies [1]." The data on the impact of COVID-19 on dental health is limited. Dziesdzic and Wojtyczka noted that the soft tissue inflammation could result in tooth loss in patients with COVID-19 [2]. Halboub et al. noted that there were various oral problems in COVID-19 patients but there were few reports on the dental problems [3]. However, the pathogenesis that the SARS CoV2 might cause dental prolems is not well clarified. In the present report, there might be an association between DD stage and the severity and prognosis of the disease. Nevertheless, there is no data on the dental health status background of the subjects in the study. The radiological finding might represent underlying dental problems that might have effects on COVID-19. The pathological bacteria at periodontal space in a COVID-19 patient with periodontitis might be aspirated and cause superimposed bacterial infection [4]. This is a possible pathogenesis of severe lung disorder in a COVID19 patient with poor dental health. Nevertheless, the observation by Dziesdzic and Wojtyczka might be confounded by many factors. The important confounding factors are personal illness (such as diabetes) and treatment. To assess the relationship between the DD stage and the severity and prognosis of COVID-19, it is necessary to control the effect of confounding factors.
Acknowledgements None.

Author contributions Both authors have equal contributions and approve for final submission.

Funding None.

Declarartions

Conflict of interest The authors declare that there is no conflict of interest.

Ethical approval None.

\section{References}

1. Sirin DA, Ozcelik F. The relationship between COVID-19 and the dental damage stage determined by radiological examination. Oral Radiol. 2021;3:1-10. https://doi.org/10.1007/ s11282-020-00497-0.

2. Dziedzicc A, Wojtyczka R. The impact of coronavirus infectious disease 19 (COVID-19) on oral health. Oral Dis. 2020. https://doi. org/10.1111/odi.13359.

3. Halboub E, Al-Maweri SA, Alanazi RH, Qaid NM, Abdulrab S. Orofacial manifestations of COVID-19: a brief review of the published literature. Braz Oral Res. 2020;30(34):e124.

4. Takahashi Y, Watanabe N, Kamio N, Yokoe S, Suzuki R, Sato S, Iinuma T, Imai K. Expression of the SARS-CoV-2 receptor ACE2 and proinflammatory cytokines induced by the periodontopathic bacterium fusobacteriumnucleatum in human respiratory epithelial cells. Int J MolSci. 2021;22(3):1352. https://doi.org/10.3390/ ijms22031352.

Publisher's Note Springer Nature remains neutral with regard to jurisdictional claims in published maps and institutional affiliations.
Rujitika Mungmunpuntipantip

rujittika@gmail.com

Private Academic Consultant Center, Bangkok, Thailand

2 Dr DY Patil University, Pune, India 